\title{
O ENSINO DE SUSTENTABILIDADE NAS CIÊNCIAS ECONÔMICAS: PERSPECTIVA CRITICA E ELEMENTOS NORTEADORES DO DEBATE
}

\section{DANIEL CAIXETA ANDRADE}

Doutor em Desenvolvimento Econômico pela Universidade Estadual de Campinas - UNICAMP, Brasil. Professor adjunto do Instituto de Economia e Relações Internacionais da Universidade Federal de Uberlândia IERI, Brasil.

daniel.andrade@ufu.br

\section{CARLOS EDUARDO DE LIMA}

Mestre em Administração pela Universidade Estadual de Londrina - UEL, Brasil.

Professor na Faculdades Integradas do Vale do Ivaí - Univale, Brasil.

carloseduardodelima@gmail.com

\begin{abstract}
Resumo
Partindo da premissa de que a academia tem um papel crucial na disseminação do conceito e meios para se atingir o chamado desenvolvimento sustentável, este ensaio tem como objetivo discutir a forma com a qual este debate é conduzido pelas ciências econômicas, cujo objeto de análise é o sistema econômico, principal veículo de alteração quantitativa e qualitativa do meio ambiente. Os economistas devem estar preparados para conduzir um debate adequado sobre as condições necessárias para a obtenção de critérios de sustentabilidade. Este não tem sido o caso, visto que o esquema analítico convencional da economia possui algumas hipóteses e premissas que resultam em um debate incompleto sobre a temática ambiental. Em função disso, são discutidos alguns princípios fundamentais que devem ser observados, evidenciando-se a importância do conceito de resiliência na análise econômica.
\end{abstract}

Palavras-chave: desenvolvimento sustentável, resiliência, bem-estar, limites termodinâmicos, economia da sustentabilidade. 


\title{
TEACHING OF SUSTAINABILITY IN ECONOMIC SCIENCES: A CRITICAL PERSPECTIVE AND ELEMENTS TO GUIDE DISCUSSIONS
}

\begin{abstract}
Starting from the premise that the academic world plays a key role in disseminating the concept and means to achieve the so-called sustainable development, this essay aims at discussing the way the economics science is conducting this debate, which the main research object is the economic system, the main vehicle of quantitative and qualitative change of the environment. Economists should be prepared to face an adequate and suitable debate about the necessary conditions for obtaining sustainability criteria. This has not been the case since the conventional analytical framework of economic science holds some hypotheses and assumptions that result in an incomplete debate on environmental issues. Given this situation, we discuss some fundamental principles that should be observed, stressing the relevance of the resilience concept for the economic analysis.
\end{abstract}

Keywords: sustainable development, resilience, well-being, thermodynamic limits, sustainability economics.

\section{LA ENSEÑANZA DE SUSTENTABILIDAD EN LAS CIENCIAS ECONÓMICAS: PERSPECTIVA CRITICA Y ELEMENTOS NORTEADORES DE DEBATE}

\begin{abstract}
Resumen
Partiendo de la premisa de que la academia tiene un papel crucial en la diseminación del concepto y medios para alcanzar el llamado desarrollo sostenible, este artículo tiene como objetivo discutir la forma con la cual este debate es conducido por las ciencias económicas, cuyo objeto de análisis es el sistema económico, principal vehículo de alteración cuantitativa y cualitativa del medio ambiente. Los economistas deben estar preparados para conducir un debate adecuado sobre las condiciones necesarias para la obtención de criterios de sustentabilidad. Este no ha sido el caso, visto que el esquema analítico convencional de la economía posee algunas hipótesis y premisas que resultan en un debate incompleto sobre la temática ambiental. En función de eso, son discutidos algunos principios fundamentales que deben ser observados, evidenciando la importancia del concepto de resiliencia en el análisis económico.

Palabras clave: desarrollo sustentable, resiliencia, bienestar, límites termodinámicos, economía de la sustentabilidad.
\end{abstract}




\section{INTRODUÇÃO}

Evidências empíricas atestam que as atividades econômicas - e antrópicas em geral - têm conduzido o planeta Terra a um estado de alerta no que diz respeito à destruição da base natural que sustenta a vida das espécies humanas e não humanas (Rockström, 2009; Barnosky Aadly, Smith 2012). Tais evidências apontam para um quadro em que a resiliência dos ecossistemas tem sido ultrapassada, o que pode significar mudanças adversas, talvez irreversíveis e catastróficas. Em meio a este contexto de crise do regime socioeconômico-ecológico, surge e se consolida o debate ambiental nas esferas acadêmica e política, tendo como carro chefe a ideia de sustentabilidade. Partindo da premissa de que a academia tem um papel crucial na disseminação do conceito e meios para se atingir o chamado desenvolvimento sustentável, este ensaio tem como objetivo discutir a forma com a qual este debate é conduzido pelas ciências econômicas. A justificativa para se discutir especificamente a economia enquanto ciência é que o economista é, por excelência, o profissional que compreende a dinâmica do sistema econômico, principal veículo de alteração do meio ambiente.

É neste sentido que os cursos de economia devem incorporar de maneira satisfatória o debate sobre sustentabilidade ambiental com uma compreensão adequada sobre as interfaces entre os sistemas econômico e natural. Todavia, verifica-se que este não é caso em função de pelo menos três motivos: i) visão pré-analítica equivocada da teoria econômica convencional; ii) não se dá a devida atenção para o conceito de resiliência ecossistêmica; iii) incompatibilidade das hipóteses implícitas sobre 0 comportamento do agente econômico. Este trabalho contribui para o debate na medida em que discute as várias abordagens do ensino de sustentabilidade em economia (economia ambiental neoclássica e economia ecológica), apresentando suas vantagens e desvantagens, além de indicar uma estrutura analítica comum para que desenvolvimento sustentável seja discutida de forma holística.

O ensaio está assim estruturado: além desta introdução e das considerações ao final, a seção seguinte faz uma breve análise sobre a inserção de temas socioambientais na educação e nas Ciências Econômicas. Posteriormente, descreve-se a origem das preocupações ambientais dentro das ciências econômicas. A quarta seção descreve sucintamente as duas abordagens comumente usadas pelos economistas para debater a temática sustentabilidade. A quinta seção resume alguns pontos que são considerados imprescindiveis para nortear o debate dos economistas sobre sustentabilidade. Nas considerações finais, são reforçados dois pontos cruciais: i) a temática de sustentabilidade está inserida no corpo teórico da economia, mas o mainstream da teoria econômica não trata adequadamente o tema; ii) os economistas devem incorporar o conceito de resiliência no seu esquema analítico como pré-requisito para uma discussão apropriada sobre sustentabilidade.

\section{EDUCAÇÃO PARA SUSTENTABILIDADE E SUA INSERÇÃO NAS CIÊNCIAS ECONÔMICAS}

Durante as últimas décadas, um número crescente de Instituições de Ensino Superior (IES) têem se empenhado na institucionalização de princípios da sustentabilidade em seus currículos, pesquisa e demais atividades (Lozano \& Young, 2013). Essas ações são resultado de um período de esforços iniciados, notadamente, na década de 1990, com intuito de reavaliar o papel da universidade diante de um novo paradigma de desenvolvimento, o sustentável. Wright (2002), Lima (2016), Grindsted (2011) e Green (2015) destacam que ao menos três grandes encontros mundiais discutiram o papel da universidade frente aos problemas socioambientais, sendo eles o de Talloires (França-1990), Halifax (Canadá-1991) e Swansea (Suécia-1993).

Como resultante desses eventos, surgiram documentos e declarações, entre outras diretrizes, que: i) afirmam que as universidades desempenham papel crucial na educação, investigação, formação

OS, Organizações e Sustentabilidade, 6(2), p. 27-41, Londrina, PR, jul./dez. 2018,

ISSN 2318-9223, http://www.uel.br/revistas/uel/index.php/ros/issue/view/1478/showToc 
de políticas e troca de informações necessárias à concretização de valores sustentáveis; ii) estabelecem programas para a produção de conhecimentos na gestão ambiental, desenvolvimento econômico sustentável e áreas afins, almejando assegurar que os estudantes sejam ambientalmente instruídos e tenham consciência e compreensão para serem cidadãos ecologicamente responsáveis; e, iii) convocam as universidades a cooperarem entre si e com todos os segmentos da sociedade na busca de medidas práticas e políticas para alcançar o desenvolvimento sustentável e, assim, salvaguardar os interesses das gerações futuras (Lima, 2016).

Na década de 2000, outro importante marco foi o lançamento da Década da Educação para o Desenvolvimento Sustentável (2005 a 2014), idealizada pelas Organização das Nações Unidas para a Educação, a Ciência e a Cultura (UNESCO). Essa ação teve o objetivo de integrar os valores inerentes ao desenvolvimento sustentável em todos os aspectos da aprendizagem e fomentar mudanças de comportamento afim de criar uma sociedade sustentável e mais justa para todos (Unesco, 2005). Para a Unesco, a maior parte deste desafio é estimular mudanças de atitude e comportamento na sociedade mundial, uma vez que nossas capacidades intelectuais, morais e culturais impõem responsabilidades para com todos os seres vivos e para com a natureza como um todo.

Segundo a Unesco (2006), a educação para o desenvolvimento sustentável deve compartilhar as características de qualquer experiência de aprendizagem de alta qualidade, com o critério adicional de que o processo de ensino e aprendizagem deva modelar os valores do próprio desenvolvimento sustentável. Assim, a educação neste sentido será moldada por uma gama de perspectivas de todos os campos de desenvolvimento humano (Unesco, 2005).

Barth, Godemann, Rieckmann, \& Stoltenberg (2007) destacam que as universidades são elementos fundamentais nesse processo, pois, além de desempenhar importante papel no processo de produção e disseminação de conhecimento, são capazes de propiciar tanto a aprendizagem formal quanto a informal. Ainda segundo os autores, a educação de nível superior, quando orientada para o desenvolvimento sustentável e a sustentabilidade, alcança resultados que vão além da aquisição e geração de conhecimento por ter efeitos adicionais, entre eles, a complexidade do comportamento e das decisões em uma perspectiva global de responsabilidade orientada para o futuro, num processo participativo.

Enquanto para algumas áreas esta percepção de mudança de currículos e práticas direcionadas à adesão à sustentabilidade já se traduziu em ações concretas, nas Ciências Econômicas, este discurso ainda soa um tanto estranho. Para Green (2013), a área de economia ortodoxa apresentada nas salas de aula construiu-se a partir de um modelo baseado nos mercados perfeitamente competitivos, em que as empresas procuram maximizar seus lucros e os indivíduos racionais autointeressados possuem demandas insaciáveis em consumir bens e serviços e tentar otimizar a sua utilidade. Por essa razão, as preocupações da área se iniciaram pela dimensão ambiental e essa trajetória será descrita na próxima seção.

\section{ORIGEM DAS PREOCUPAÇÕES AMBIENTAIS NAS CIÊNCIAS ECONÔMICAS: UM BREVE RETROSPECTO}

Para se discutir a ideia de sustentabilidade na teoria econômica é preciso que se retroceda um pouco no tempo a fim de que se possa ter uma correta compreensão a respeito das diferentes visões sobre o relacionamento entre o sistema econômico e o meio ambiente. Independentemente do tempo e do espaço, todos os estudiosos que se debruçaram sobre o tema são unânimes em dizer que o meio natural é o suporte básico sobre o qual se assentam as relações socioeconômicas. As discrepâncias existentes entre as diferentes interpretações sobre a sustentabilidade estão ligadas à maneira como se identifica a natureza das relações entre o sistema econômico e o meio ambiente.

OS, Organizações e Sustentabilidade, 6(2), p. 27-41, Londrina, PR, jul./dez. 2018, 
A preocupação com os limites ambientais ao crescimento econômico pode ser encontrada já nos trabalhos dos chamados economistas clássicos, como Adam Smith, David Ricardo e John Stuart Mill. Em seus modelos de crescimento, construídos nos séculos XVIII e XIX, esses autores postulavam a necessidade de um "estado-estacionário" (inicialmente, stationary state, porém mais tarde conhecido como steady state, "estado estável"), na medida em que a finitude dos recursos naturais e a impossibilidade de crescimento ilimitado da produtividade apresentavam-se como um empecilho à continuidade da expansão do sistema econômico.

Com a emergência da escola neoclássica (segunda metade do século XIX), a ideia de um obstáculo absoluto ao crescimento imposto pelo meio ambiente é substituída pela crença no avanço tecnológico como elemento chave capaz de relativizar indefinidamente os limites ambientais ao crescimento econômico. A tradição neoclássica procurou legitimar cientificamente a convicção de que o sistema capitalista e os padrões de consumo dele decorrentes não seriam obstados pelo meio natural. Ao mesmo tempo em que reconhece a existência de possiveis problemas decorrentes da degradação ambiental, esta escola postula que crescimento econômico extra é capaz de solucionálos, bem como aumentar o bem-estar e senso de justiça dentro das sociedades (Friedman, 2005; Grossman \& Grueger, 1995). As possibilidades de substituição dos recursos naturais por outros fatores de produção, mormente trabalho e capital reprodutivel, juntamente com os avanços no progresso tecnológico, eliminariam os óbices trazidos pela escassez provocada pela depleção dos ecossistemas e recursos naturais (Solow, 1974).

A década de 1960 assistiu a uma intensificação do debate ambiental. As principais obras publicadas na época sobre a problemática do meio ambiente (Carson, 1962; Ehrlich, 1968; Hardin, 1968) fizeram com que ela fosse também introduzida no cenário acadêmico. Foi também neste período que houve o primeiro arranjo científico destinado a reunir pesquisadores preocupados com o excesso de poluição e degradação causado pelo crescimento econômico. Trata-se do famoso Clube de Roma, criado em 1968, cuja influência marcou o rumo do debate ambiental nas duas décadas seguintes.

O ponto de vista dos participantes do Clube de Roma é explicitado no conhecido Relatório Meadows ou simplesmente "Limits to Growth" (Meadows et al.,1972; Nørgård, 2010). A obra aponta para um cenário de impossibilidade de perpetuação do crescimento econômico devido à exaustão dos recursos ambientais por ele acarretada, levantando assim a proposta de um crescimento econômico "zero". O debate passa então a polarizar-se entre esta posição de "crescimento zero" - conhecida por "neomalthusiana" - e posições desenvolvimentistas de "direito ao crescimento", defendida, inclusive, pelos países em via de desenvolvimento.

A publicação do Relatório Meadows coincidiu com a primeira reunião da Organização das Nações Unidas sobre Meio Ambiente Humano, realizada em Estocolmo, Suécia, também no ano de 1972. Há quem argumente que a publicação do relatório naquele ano foi proposital, uma vez que a intenção era estabelecer o marco das discussões sobre crescimento econômico e meio ambiente durante tal reunião. A despeito desta suspeição, o fato é que o relatório Meadows se consolidou como uma peça chave para capitanear o debate sobre a relação entre crescimento econômico e preservação ambiental nas arenas políticas e acadêmica. Com efeito, o conteúdo do relatório Meadows - que em linhas gerais aponta para a impossibilidade de a biosfera absorver indefinidamente o crescimento populacional e material da espécie humana - é o marco do debate ambiental do final do século XXe peça fundamental para um processo de discussão que culminaria na institucionalização da temática ambiental em âmbito mundial (Nørgård, 2010).

Mas o que, afinal, trazia o relatório Meadows? O documento, encomendado pelo Clube de Roma e elaborado por pesquisadores do Massachusetts Institute of Technology (MIT), utilizou-se de um modelo computacional (World3) que trouxe resultados alarmantes no sentido de apontar a iminência de uma catástrofe ambiental caso a trajetória de expansão do sistema econômico se 
mantivesse. A pressão sobre os recursos naturais do planeta e a poluição gerada pelo crescimento econômico desequilibrariam o ecossistema terrestre e haveria uma rápida reversão nas condições de vida no planeta.

A visão catastrófica de Limits to Growth marcou decisivamente a clivagem entre os partidários da continuidade do crescimento econômico (panglossianos) e aqueles defensores do crescimento "zero" (os chamados neomalthusianos). Tal polarização caracteriza o debate ambiental da década de 1970 e impôs obstáculos para o avanço das discussões travadas sobre o tema. A questão da preservação ambiental adquiriu status internacional enquanto importante pauta na formulação de políticas econômicas, adentrando definitivamente o debate político e acadêmico.

Ainda na década de 1970 foi formalizado o conceito de ecodesenvolvimento, cuja motivação foi pavimentar os fundamentos teóricos para a discussão sobre um novo modelo de desenvolvimento capaz de conciliar as questões econômicas, sociais e ambientais de modo a permitir a solução do dilema de crescimento e preservação do capital natural. Todavia, o fôlego do conceito de ecodesenvolvimento foi limitado e sua disseminação e utilização foi efêmera, já que a publicação do Relatório Brundtland ou Our Common Future (Brundtland, 1987) consolida-se como importante avanço no comprometimento com um desenvolvimento mais consciente de suas consequências ambientais e também enquanto marco formal da mais difundida conceituação do que realmente seria o desenvolvimento sustentável. O relatório identifica as principais bases sobre as quais deveria ser construído este novo modelo de desenvolvimento que pudesse conciliar as necessidades econômicas, o imperativo de conservação ambiental e a desejável justiça social.

Segundo Amazonas (2002), embora tenha se alcançado unanimidade quase universal, pode-se dizer que a incorporação do conceito de Desenvolvimento Sustentável pelo esquema analítico convencional da teoria econômica foi feita de maneira truncada, uma vez que as próprias premissas e hipóteses constitutivas da teoria neoclássica são conflitantes com os princípios implícitos no conceito de Desenvolvimento Sustentável.

Já no que tange ao próprio conceito de sustentabilidade, sua origem é dada pelo debate entre aqueles que acreditavam na ausência de um dilema entre conservação ambiental e crescimento econômico e aqueles que creem no contrário, uma vez que o debate científico internacional era regido pela hipótese otimista de que o crescimento econômico só prejudicaria a natureza até um dado momento de riqueza adquirida, sendo que logo em seguida a tendência seria a melhoria da qualidade de vida e das condições ambientais ${ }^{1}$ (Veiga, 2005). Os desdobramentos deste debate resultaram em diferentes abordagens de tratamento da sustentabilidade dentro das ciências econômicas. Os princípios fundamentais das duas principais vertentes são brevemente revisados na próxima seção.

\section{PRINCIPAIS ABORDAGENS DO DISCURSO SOBRE SUSTENTABILIDADE NAS CIÊNCIAS ECONÔMICAS}

O conceito de sustentabilidade é amplo, complexo e agrega várias dimensões. No que tange à economia do meio ambiente, parte das ciências econômicas que se dedica ao estudo das interrelações entre desenvolvimento socioeconômico e meio ambiente, a diversidade deste tema se evidencia por meio de suas principais abordagens, que serão descritas nesta seção.

\footnotetext{
${ }^{1}$ A hipótese de que nos estágios iniciais do processo de crescimento econômico haveria um aumento da degradação ambiental, mas que este, por si só, engendraria posteriormente uma redução na deterioração ambiental ficou conhecida como Curva Ambiental de Kuznets, em referência ao estudo clássico de Śmon Kuznets de 1956 (Grossman \& Grueger, 1995).
}

OS, Organizações e Sustentabilidade, 6(2), p. 27-41, Londrina, PR, jul./dez. 2018, 


\section{A abordagem Neoclássica: SustentabiLidade Subsumida À Ideia de Crescimento Econômico}

A organização econômica de uma sociedade é resultado de um longo processo histórico ao qual se impõem determinadas modalidades de produção, distribuição e troca de consumos e produtos. 0 sistema capitalista tem no mercado o instrumento pelo qual se estabelece tal organização econômica. Durante séculos o mercado foi considerado o mecanismo de alocação de recursos e capaz de possibilitar que o que fosse considerado o ótimo para uma pessoa se convertesse em um bem comum por meio da mão invisível. Esse pressuposto, porém, era restrito à economia, ou seja, bens e serviços que, por meio de seus preços, se intercambiavam no mercado. Até então, a análise econômica desconsiderava as bases naturais por meio das quais a produção se sustentava, assim como os resíduos oriundos desse processo (Foladori, 2001; Montibeller-Filho, 2008).

A teoria ambiental neoclássica surgiu a partir do momento em que o mainstream econômico se viu compelido (e pressionado) a incorporar em seu esquema analítico considerações acerca da problemática ambiental. Isso porque o sistema econômico é visto como a principal fonte de pressão sobre o meio ambiente, sendo necessário, pois, que a análise econômica dominante apresentasse respostas sobre sua relação traumática com os sistemas naturais (Andrade, 2008).

A corrente neoclássica tornou-se majoritária na economia do meio ambiente por considerar grande parte das outras linhas de pensamento econômico. Neste aspecto, o conceito de externalidade foi incorporado ao se analisar os efeitos das atividades produtivas sobre o meio ambiente. As externalidades ocorrem quando o consumo e/ou a produção de um determinado bem afetam outros consumidores ou produtores, em outros mercados. É importante acrescentar que essas externalidades podem ser positivas (benefícios externos) ou negativas (custos externos) (Foladori, 2001).

Nas décadas de 1920, Artur Pigou sustentava a necessidade de que as externalidades negativas fossem contempladas pelo Estado, impondo aos seus responsáveis uma taxa que deveria ser a diferença entre o custo social e o custo privado. No caso de uma indústria poluidora, por exemplo, essa diferença (custo externo) corresponde aos custos dos mecanismos necessários para purificar o ar até o nivel anterior, ou indenizar os Estados. Em suma, o Estado corrigiria as falhas de mercado; todavia, este continuaria sendo o mecanismo alocador do recurso (Foladori, 2001).

Outra contribuição ao conceito de externalidades foi elaborada por Ronald Coase em 1960. Seu pressuposto baseia-se na afirmação de que as externalidades negativas seriam resultado da ausência de propriedade privada sobre os bens comuns. Atribuindo direitos de propriedade sobre os recursos e serviços ambientais, seus proprietários poderiam comercializá-los com o agente explorador do recurso ou serviço, fazendo com que a externalidade fosse internalizada e o nível da atividade econômica e de controle ambiental chegassem ao ponto "ótimo" via negociação entre os agentes (Montibeller-Filho, 2008). Este seria o princípio geral que ficou conhecido na literatura como "negociação coaseana".

Ainda considerando os princípios neoclássicos na alocação dos recursos naturais e o funcionamento dos mecanismos de preço aplicados a estes, Santos (2007) afirma que, conforme os recursos vão se exaurindo, seus preços aumentam, diminuindo sua demanda e, assim, voltando a aumentar sua qualidade, o que pode ser representado por uma espécie de curva de Kuznets Ambiental. Esta, por sua vez, pode ser explicada também pelo fato de que, à medida que a renda aumenta pelo crescimento econômico, existe um aumento da degradação ambiental até o ponto em que o custo dela e as preferências do consumidor fazem com que mudanças institucionais e tecnológicas promovam a recuperação do recurso degradado, revelando que existe uma aceitação pela sociedade da degradação ambiental pela aparente inviabilidade desta para o desenvolvimento econômico.

OS, Organizações e Sustentabilidade, 6(2), p. 27-41, Londrina, PR, jul./dez. 2018,

ISSN 2318-9223, http://www.uel.br/revistas/uel/index.php/ros/issue/view/1478/showToc 
De maneira geral, a economia ambiental neoclássica não rompe com o velho modelo economicista de crescimento econômico, deixando sua contribuição focada na monetização dos recursos naturais e dos resíduos do processo produtivo. Seus pressupostos não rompem com padrões de produção e consumo capazes de degradar os ecossistemas e não levar em conta suas peculiaridades. Quando considerado o contexto da sustentabilidade, esta corrente se demonstra ainda mais frágil, pois não aborda diretamente as questões ligadas à dimensão social do conceito. Além disso, a economia ambiental neoclássica assume a possibilidade de substituição indefinida de fatores dentro do processo de produção.

Na concepção de Amazonas (2002), a hipótese de substituibilidade perfeita entre os fatores de produção conduz à falácia de que o capital natural pode ser indefinidamente substituído pelo capital manufaturado pelo homem (princípio da sustentabilidade fraca). Neste tipo de análise, o critério de sustentabilidade é facilmente obtido, já que ele seria condicionado pela capacidade de produção de artefatos humanos (capital produzido) para substituir ou repor o capital natural exaurido. Daí a ideia de que a sustentabilidade seria subsumida pelo crescimento econômico.

\section{A abordagem Econômico-Ecológica e a Centralidade dos Limites Biofisicos}

A institucionalização da economia ecológica no contexto acadêmico e científico é um fenômeno relativamente recente. Este novo ramo foi estruturado de modo formal em $1989 \mathrm{com}$ a fundação da International Society for Ecological Economics (ISEE) e com o periódico Ecological Economics. A decisão de estruturação da economia ecológica se deu em 1987, por ocasião de uma conferência realizada em Barcelona, em que foi evidenciada a insatisfação de pesquisadores (tanto do ramo da economia como no das ciências naturais) com o potencial da teoria econômica neoclássica em propor soluções adequadas para problemas ambientais relevantes e com o seu enfoque reducionista (Andrade, 2008).

As origens das ideias que hoje fazem parte da estrutura analítica da Economia Ecológica são encontradas, principalmente, nos trabalhos de Boulding (1966), Daly (1968) e Georgescu-Roegen (1971), os quais lançaram as bases para a crítica do enfoque neoclássico dos problemas ambientais, principalmente no que diz respeito às desconsiderações das leis da termodinâmica no processo econômico e suas implicações para o principal problema da ciência econômica (a escassez)².

A economia ecológica contempla o estudo da estrutura e o processo econômico de geossistemas ${ }^{3}$ sob a ótica dos fluxos físicos de energia e de materiais. Para Foladori (2001), a análise da economia ecológica parte dos fluxos de energia e se fundamenta nas duas leis da termodinâmica, cujos princípios foram cristalizados em 1824, quando Sadi Carnot (1796-1832) escreveu os resultados de sua investigação, sendo eles: i) Primeira Lei da Termodinâmica: em um sistema isolado (fechado) a energia total (soma de todas as formas, por exemplo, mecânica, química, térmica, elétrica) é constante; ii) Segunda Lei da Termodinâmica: a energia flui em uma só direção e tende a se dissipar em calor de baixa temperatura, que não pode ser utilizado. Chama-se entropia essa soma de energia não aproveitável.

\footnotetext{
2 Para uma revisão mais detalhada sobre a evolução das ideias que conformam hoje a Economia Ecológica, ver Ropke (2004).

${ }^{3}$ Os geossistemas são a representação da organização espacial resultante da interação dos componentes físicos da natureza (sistemas), aí incluídos clima, topografia, rochas, águas, vegetação e solos, entre outros, podendo ou não estarem todos esses componentes presentes. É uma classe particular de sistemas dirigidos, sendo o espaço terrestre de todas as dimensões, onde os componentes individuais da natureza se encontram numa relação sistêmica uns com os outros e, com uma determinada integridade, interatuam com a esfera cósmica e com a sociedade humana (Sotchava, 1978)
}

OS, Organizações e Sustentabilidade, 6(2), p. 27-41, Londrina, PR, jul./dez. 2018, 
No plano da teoria econômica, o trabalho do matemático e economista romeno Georgescu-Roengen, publicado no ano de 1971 e denominado The Entropy law and Economic Process (Ceorgescu-Roegen, 1971), inseriu no estudo econômico a lei da entropia ao contemplar a segunda lei da termodinâmica. Desde então, o raciocínio econômico foi radicalmente alterado na medida em que houve a inserção da ideia de irreversibilidade e de limites na teoria econômica convencional (Romeiro, 2009). Um dos principais impactos da inserção da ideia de entropia no contexto econômico foi a mudança da visão da economia como circular ou espiral de valor de troca para um fluxo entrópico de energia e materiais.

Em resumo, a proposta da economia ecológica é a de tentar compreender a dinâmica do sistema econômico com base em seus fluxos materiais e energéticos, partindo-se da premissa de que o sistema econômico é aberto e heterótrofo, o que significa que é preciso que ele absorva e expila matéria e energia do meio exterior para viabilizar a sua expansão. O problema é que, ao longo desse processo de expansão, o sistema econômico altera quantitativa e qualitativamente o meio ambiente.

A economia ecológica traz implícita a ideia de uma agenda de pesquisa verdadeiramente transdisciplinar, cujo fulcro pode ser associado ao objetivo último do desenvolvimento sustentável, entendido como a equidade intra e intergeracional (Andrade, 2008). Sob o enfoque ecológico, a economia passa a ser considerada apenas uma parte de um todo, por esse motivo a relevância de outras variáveis passam a ser consideradas fundamentais. Isso significa que a abordagem econômico-ecológica tenta fugir do reducionismo puramente economicista e adota uma postura de transdisciplinaridade e pluralismo metodológico.

A perspectiva da economia ecológica tem uma visão mais cética com relação às possibilidades de obtenção do critério de sustentabilidade. Isso porque ela parte da crítica original de CeogescuRoegen (1971), para quem os fatores de produção possuem papéis distintos dentro do processo produtivo. Como tal, tais fatores nunca poderiam ser perfeitamente substitutos entre si, já que alguns são recursos totalmente transformados (recursos naturais, por exemplo) ao longo da produção de bens e serviços, enquanto que outros são agentes que viabilizam tal transformação (capital e trabalho humanos). Enquanto os primeiros são completamente consumidos, a segunda categoria apenas é gasta na produção. Em função destas características, os fatores de produção só podem ser complementares, originando assim o princípio da sustentabilidade forte.

Por fim, a abordagem econômico-ecológica se diferencia na medida em que sua visão pré-analítica concebe o sistema econômico como um subsistema do ecossistema terrestre. Este último limita a expansão física do sistema econômico e o grande desafio passa a ser o compreender a dinâmica de um sistema que é biofisicamente limitado pelo seu sistema maior (o meio ambiente). Em função disso, os limites biofísicos são centrais neste tipo de análise (Andrade \& Vale, 2014).

\section{ELEMENTOS NORTEADORES PARA O DEBATE SOBRE SUSTENTABILIDADE DENTRO DAS CIÊNCIAS ECONÔMICAS}

A seção anterior procurou descrever brevemente as abordagens que refletem o modo com que os economistas discutem o tema de sustentabilidade em seu arcabouço teórico. A diversidade de abordagens se deve em primeira instância ao caráter de ciência social aplicada, assumido pelas ciências econômicas. Em função disso, não há unanimidade sobre todos os temas tratados no âmbito da economia. Exemplo disso é o perene debate sobre a capacidade ou incapacidade de o mercado se autorregular, o que vem pontuando o debate entre os defensores do livre mercado e aqueles que advogam o intervencionismo do Estado.

No que diz respeito ao debate sobre sustentabilidade, é fato que esta temática foi incorporada nas discussões econômicas. A existência de uma disciplina de economia do meio ambiente em alguns

OS, Organizações e Sustentabilidade, 6(2), p. 27-41, Londrina, PR, jul./dez. 2018,

ISSN 2318-9223, http://www.uel.br/revistas/uel/index.php/ros/issue/view/1478/showToc 
currículos ${ }^{4}$ das universidades brasileiras comprova que o tema vem merecendo destaque por parte dos economistas. Para além disso, a existência de extensa literatura econômica que trata de questões ambientais atesta que a temática está institucionalizada. Um bom exemplo de incorporação crescente dela no debate econômico pode ser encontrado em Arnt (2010), em que importantes economistas brasileiros, tanto do mainstream econômico como de correntes mais críticas, apresentam suas percepções sobre a sustentabilidade e as possibilidades de desenvolvimento econômico no atual cenário de degradação do capital natural terrestre. Não obstante as divergências, as opiniões ali expressas permitem extrair a interpretação de que o debate ambiental se consolidou como obrigatório na análise econômica, muito embora o tratamento dado à questão seja frequentemente reducionista e/ou insatisfatório.

O problema é que, mesmo considerando a sua "boa fé", a visão dos economistas sobre a sustentabilidade é equivocada, devido, principalmente, a algumas hipóteses adotadas pela teoria convencional sobre o processo econômico (Chechin \& Veiga, 2010; Mueller, 2005). A visão dominante é de que a sustentabilidade é um problema de manutenção de estoque de capital e que as possibilidades de desenvolvimento sustentável estão atreladas ao grau de substituibilidade entre capital natural e produzido e à marcha do progresso tecnológico.

De maneira geral, o debate sobre sustentabilidade dentro das ciências econômicas deve ser pontuado pelo seguinte problema de pesquisa: por que os economistas convencionais têm uma visão limitada de sustentabilidade e quais são os aspectos importantes que devem ser incluídos no debate a fim de que se possa ter uma compreensão mais holística das relações entre sistema econômico e meio ambiente? A partir deste questionamento, há de se compreender as premissas fundamentais que levam a teoria econômica convencional a uma visão reducionista sobre sustentabilidade. Ao mesmo tempo, há de se investigar os pré-requisitos para se ampliar o escopo de análise da sustentabilidade.

Além de alocar e preservar os recursos, uma definição razoável de ciências econômicas requer que sejam claramente definidos os objetivos a serem alcançados (bem como o modo pelo qual eles devem ser perseguidos), com quais tipos de recursos se está tratando, quais são suas características e como (e por quem) deve ser feita sua alocação e preservação. No que se refere aos objetivos perseguidos, é consenso que o aumento do bem-estar geral e incremento na qualidade de vida têm sido, explícita ou implicitamente, os principais objetivos de política para os indivíduos, comunidades e nações.

Dentro da visão econômica mainstream, o crescimento econômico ilimitado é tido como sendo o principal veículo de obtenção dos objetivos da sociedade e o fim último da política econômica (growthmania). Todavia, existem evidências abundantes de que maior crescimento material não necessariamente conduz a um aumento do bem-estar e da felicidade humana (Easterlin, 2003). Este fato pressupõe a necessidade de reavaliação dos meios possiveis para uma melhoria qualitativa das condições de vida, não baseada exclusivamente no crescimento econômico.

A característica de escassez atribuída ao capital natural, considerado tanto do ponto de vista de um de conjunto de ativos tangiveis (recursos naturais) como em sua dimensão de fornecedor de benefícios úteis para o bem-estar humano - os chamados serviços ecossistêmicos (Daily, 1997) -, foi historicamente alvo das análises de economistas preocupados com a possibilidade de que essa escassez viesse a se configurar um obstáculo ao crescimento econômico.

\footnotetext{
${ }^{4}$ Em grande parte dos cursos de graduação em ciências econômicas das universidades, a disciplina de economia do meio ambiente é apenas oferecida como optativa, o que demonstra que, apesar da reconhecida importância do tema, a sustentabilidade e o meio ambiente ainda não fazem parte da formação básica do economista no Brasil.
}

OS, Organizações e Sustentabilidade, 6(2), p. 27-41, Londrina, PR, jul./dez. 2018, 
Existem alguns aspectos interessantes nas premissas implícitas no esquema analítico convencional, responsáveis por tornar a preservação do capital natural um tema não relevante ao hardcore da ciência econômica. Embora sempre se tivesse o conhecimento da natureza escassa e finita de alguns recursos naturais, a questão básica para a qual se deve buscar uma compreensão mais aprofundada passa a ser o descolamento dos objetivos de alocação eficiente e preservação dos recursos. Enquanto o primeiro foi eleito como o objetivo único da ciência econômica, o segundo assumiu um papel secundário ou mesmo inexistente, mesmo sendo senso comum de que a alocação pode ser totalmente inviabilizada pela inexistência do próprio capital natural.

A fim de avançar na compreensão de como os sistemas econômicos podem se tornar sustentáveis, o debate sobre sustentabilidade não deve ficar restringido à discussão sobre o papel dos recursos no processo de produtivo. Este tem sido o modo tradicional de encaminhamento da discussão, como foi mencionado na seção anterior. De um lado, economistas do mainstream tendem a adotar o princípio da sustentabilidade fraca como principal arcabouço para analisar as possibilidades de se atingir o desenvolvimento sustentável. De outro, economistas ecológicos se prendem à premissa de sustentabilidade forte. Esta dicotomia entre fatores substitutos versus fatores complementares deve ser superada, já que a hipótese de substituibilidade é frágil e facilmente contestada, visto que possui pouco suporte lógico e prático. Se o capital construido pelo homem fosse um substituto perfeito do capital natural, este também seria um substituto perfeito para o primeiro. Se esse fosse o caso, não haveria necessidade de produção de capital construído pelo homem, dado que o capital natural já está disponivel (Costanza \& Daly, 1992).

Partindo, pois, da constatação do caráter complementar e mutuamente dependente dos recursos naturais e aqueles produzidos pelo homem, incluindo nesta última categoria a força de trabalho humana, alguns princípios devem ser observados a fim de que o debate sobre sustentabilidade seja conduzido de maneira apropriada. São eles:

i) Sustentabilidade é um conceito amplo e complexo. Na sua vertente ambiental, torna-se um imperativo supremo já que ela condiciona a continuidade da existência das espécies humana e não humana no planeta Terra. As outras dimensões do conceito de sustentabilidade assumem um caráter normativo, já que aludem ao modo pelo qual a humanidade concebe a sua própria prosperidade;

ii) As ciências econômicas devem conceber a preservação dos recursos como a prioridade das atividades econômicas e a alocação eficiente deve estar condicionada a este objetivo (Andrade \& Romeiro, 2011);

iii) O conceito de resiliência deve ser o ponto de partida do debate sobre sustentabilidade. Conforme discutido por Arrow et al. (1995), as atividades econômicas apenas são sustentáveis quando os ecossistemas que as alicerçam são resilientes. Isto pressupõe que os economistas estejam familiarizados com este conceito e sejam capazes de monitorar minimamente a capacidade de resiliência dos sistemas naturais e econômicos ${ }^{5}$. Apesar de o conceito de resiliência ser central no debate, a ideia de sustentabilidade não pode ser subsumida à ideia de obtenção de sistemas puramente resilientes. Desenvolvimento sustentável deve aludir à maneira como a sociedade elege as prioridades para manter o seu processo de prosperidade;

iv) A natureza possui valor instrumental e intrínseco;

v) Atenção especial para com os benefícios intangiveis fornecidos pela natureza, conhecidos como serviços ecossistêmicos Millennium Ecosystem Assessment (2005);

\footnotetext{
5 Há que se reconhecer que a própria ciência ainda não é capaz de determinar o ponto a partir do qual um sistema deixa de ser resiliente. Não obstante a isso, esta preocupação deve estar presente em qualquer debate sobre sustentabilidade.
}

OS, Organizações e Sustentabilidade, 6(2), p. 27-41, Londrina, PR, jul./dez. 2018, 
vi) Os sistemas econômicos e naturais são sistemas complexos e em permanente coevolução. As interfaces entre os dois sistemas não devem ser compreendidas apenas no âmbito da troca de valores monetários, mas sim em termos biofísicos e;

vii) Necessidade de atenção permanente com a equidade intra e intergeracional.

\section{À GUISA DE CONCLUSÃO}

A trajetória da sociedade capitalista e da engrenagem econômica por ela ensejada tem sido apontada como ecologicamente insustentável, no sentido de que os sinais de degradação do capital natural e a deterioração de seus fluxos de serviços tornam-se cada vez mais claros. Entre outros, pode-se citar como exemplo a recorrência de desastres ecológicos, a mudança no clima e a contínua perda de diversidade biológica, representada pela homogeneização de paisagens naturais.

A ocorrência da mais recente crise econômica representa, em última instância, a inadequação de um modelo socioeconômico-ecológico construído sobre as premissas do capitalismo de livre mercado e do crescimento econômico ilimitado, incapaz de promover o bem-estar sustentável da sociedade humana e de garantir os mesmos padrões para as gerações futuras.

Se, de um Iado, a Economia é a ciência que se preocupa com a alocação dos recursos escassos, de outro, é preciso se perguntar quais são estes recursos escassos, quais são suas características, bem como quais são os meios para se alcançar sua alocação. Em última instância, é preciso também levar em consideração questões de preservação desses recursos. Diante disso, as ciências econômicas devem, portanto, se preocupar com a sustentabilidade das atividades econômicas e das condições mínimas para manter a viabilidade da existência da espécie humana no planeta Terra. É neste sentido que o debate sobre desenvolvimento sustentável e sustentabilidade não deve estar ausente das análises econômicas.

Apesar do consenso geral em torno do desenvolvimento sustentável, percebe-se que discussões envolvendo esse conceito são vagas e, ao mesmo tempo, opacas no sentido de que são raras depurações mais profundas sobre a operacionalização do conceito. Há quem afirme, inclusive, que a imprecisão inerente ao termo é o que lhe empresta tamanha atratividade.

De fato, alguns estudiosos do tema apontam que a própria falta de precisão do conceito de desenvolvimento sustentável é uma característica conveniente. Isto porque a origem do conceito formal de desenvolvimento sustentável se deu em função da necessidade de se abrigar sob o mesmo "guarda-chuva" posições até então conflitantes. Em outras palavras, o conceito de desenvolvimento sustentável foi criado inter alia para servir de elo unificador de visões distintas sobre a relação entre crescimento econômico e preservação ambiental. Conforme o estudioso do tema, Veiga (2005), desenvolvimento sustentável revela um enigma à espera de seu Édipo.

De maneira sucinta, a principal ideia contida no conceito de desenvolvimento sustentável é a possibilidade de manutenção para as gerações futuras de pelo menos o mesmo nível de bem-estar de que hoje gozam as gerações atuais. Segundo o relatório Brundtland (ou relatório "Nosso Futuro Comum"), o desenvolvimento sustentável pode ser entendido como "aquele desenvolvimento que permite às gerações presentes satisfazerem suas necessidades sem comprometer a capacidade de as gerações futuras satisfazerem as suas próprias" (Brundtland, 1987, p. 24). Assim colocado, 0 desenvolvimento sustentável pressupõe a igualdade de oportunidades inter e intrageracional, incluindo aí a oportunidade de desfrute de um meio ambiente saudável e equilibrado.

O sistema econômico é sem dúvida o principal veículo de modificação do meio ambiente. Através das atividades econômicas, o homem se apropria dos recursos oferecidos pela natureza e produz bens e serviços necessários à satisfação das necessidades humanas. Em sendo assim, o debate

OS, Organizações e Sustentabilidade, 6(2), p. 27-41, Londrina, PR, jul./dez. 2018,

ISSN 2318-9223, http://www.uel.br/revistas/uel/index.php/ros/issue/view/1478/showToc 
sobre sustentabilidade passa necessariamente pela consideração das relações entre sistema econômico e meio ambiente.

Os economistas não ficaram alheios à discussão sobre sustentabilidade. Ao contrário, este é um tema que vem sendo crescentemente debatido por esses profissionais. A despeito de controvérsias e visões contrastantes, a impressão geral é de que a importância do desenvolvimento sustentável para a análise econômica tem se tornado uma unanimidade entre eles.

Este ensaio teve como objetivo principal discutir alguns princípios básicos que devem nortear o debate sobre sustentabilidade dentro da análise econômico. Investigações dessa natureza contribuem para tornar mais palatável o discurso de desenvolvimento sustentável. Pessoas comuns diariamente se deparam com a expressão desenvolvimento sustentável, sem, contudo, uma explicação mínima sobre as ideias subjacentes ao conceito, muito menos sobre a origem e evolução do termo. Os próprios economistas ainda não têm uma clareza razoável sobre a problemática da sustentabilidade ambiental, fato este relacionado à histórica displicência da análise econômica com relação às questões ambientais. Muito embora a consciência de que atualmente a questão ambiental é ponto obrigatório na pauta de discussões acadêmicas e políticas, o que se nota é que ainda há muito que se avançar no debate sobre sustentabilidade ambiental.

\section{REFERÊNCIAS}

Amazonas, M. C. (2002). Economia ambiental neoclássica e desenvolvimento sustentável. In M. Nobre. \& M. C. Amazonas (Eds). Desenvolvimento sustentável: A institucionalização de um conceito. Brasília: Edições Ibama.

Andrade, D. C. (2008). Economia e meio ambiente: Aspectos teóricos e metodológicos nas visões neoclássica e da economia ecológica. Leituras de Economia Política, 14, 1-31.

Andrade, D. C., \& Romeiro, A. R. (2011). Degradação ambiental e teoria econômica: Algumas reflexões sobre uma economia dos ecossistemas. Economia, 12, 3-26.

Andrade, D. C., \& Vale, P. M. (2014). Fronteiras planetárias e limites ao crescimento: Algumas implicações de política econômica. Revista Iberoamericana de Economía Ecológica, 22, 69-84.

Arnt, R. (2010). O que os economistas pensam sobre sustentabilidade. São Paulo: Editora 34.

Arrow, K., Bolin, B., Costanza, R., Dasgupta, P., Folke, C., Holling, C.S., Jansson, B. O., Levin, S., Mäler, K. G., Perrings, C., \& Pimentel, D. (1995). Economic growth, carrying capacity, and the environment. Science, 268, 520-521.

Barnosky, A. D., Aadly, E. A. ... \& Smith, A. B. (2012). Approaching a state shift in Earth's biosphere. Nature, 486, 52-58.

Barth, M., Godemann J., Rieckman M., \& Stoltenberg U. (2007) Developing key competences for sustainable development in higher education. International Journal of Sustainability Higher Education, 8(4), 416-430.

Boulding, K. E. (1966). The economics of the coming spaceship earth. In H. Jarrett (Ed.). Environmental quality in a growing economy. Baltimore: John Hopkins University Press.

Brundtland, G. H. (1987). Our common future. Report of the World Commission of Environment and Development - United Nations.

Carson, R. (1962). Silent spring. New York: Houghton Mifflin Company.

Chechin, A., \& Veija, J. E. (2010). O fundamento central da economia ecológica. In P. H. May (ED). Economia do meio ambiente: Teoria e prática. Rio de Janeiro: Elsevier. 
Costanza, R., \& Daly, H. E. (1992). Natural capital and sustainable development. Conservation Biology, 6(1): 37-46.

Daily, G. (1997). Nature's services: Societal dependence on natural ecosystem. Washington DC: Island Press.

Easterlin, R. (2003). Explaining happiness. Proceeding of the National Academy of Sciences (PNAS), 100(19), 11176-11183.

Ehrlich, P.R. (1968). The population bomb. Cutchoghe: Buccaneer Books.

Foladori, G. (2001). Limites do desenvolvimento sustentável. Campinas, SP: Editora da UNICAMP, São Paulo.

Friedman, B. (2005.). The moral consequences of economic growth. Alfred A. Knopf: New York.

Ceorgescu-Roegen, N. (1971). The entropy law and the economic process. Cambridge: Harvard University Press.

Green, T. L. (2015). Lecturers' perspectives on how introductory economic courses address sustainability. International Journal of Sustainability in Higher Education, 16(1), 44-56.

Grindsted, T. (2011). Sustainable universities - From sustainability in higher education declarations to national law. Journal of Environmental Economics, 2, 29-36.

Grossman, G. M., \& Krueger, A. B. (1995). Economic growth and the environment. Quarterly Journal of Economics, 110(2), 353-377.

Hardin, G. (1968). The tragedy of the commons. Science, 162, 1243-1248.

Lima, C. E. (2016). A institucionalização da temática sustentabilidade em pós-graduações stricto sensu em administração no Brasil. Dissertação (Mestrado em Administração). Universidade Estadual de Londrina, Londrina.

Lozano R., \& Young W. (2012). Assessing sustainability in university curricula: Exploring the influence of student numbers and course credits. Journal of Cleaner Production, 49, 134-141.

Millennium Ecosystem Assessment. (2005). Ecosystem and Human Well-Being: Synthesis. Washington, D.C. Island Press.

Meadows, D. H., Meadows, D. L., Randers, J., \& Behrens III, W. (1972). Limits to growth. New York: Universe Books.

Montibeller-Filho, G. (2008). O mito do desenvolvimento sustentável. Florianópolis: Editora da UFSC.

Mueller, C. C. (2005). O debate dos economistas sobre a sustentabilidade: Uma avaliação sob a ótica da análise do processo produtivo de Gergescu-Roegen. Estudos Econômicos, 35(4), 687-713.

Nørgård, J. S., Peet, J., \& Ragnarsdóttir, K. V. (2010). The history of The limits to growth. Solutions, 1(2), p. 59-63.

Rockström, J., Steffen, W. ... \& Foley, J. (2009). A safe operating space for humanity. Nature, 461, 472-475.

Romeiro, A. R. (2009). Economia ou economia política da sustentabilidade. In P. May (Org.) Economia do meio ambiente. Rio de Janeiro: Campos-Elsevier.

Santos, R. B. (2007). Relações entre o meio ambiente e ciência econômica: Reflexões sobre economia ambiental e a sustentabilidade. In Anais do /l Seminário sobre sustentabilidade da FAE. 
Solow, R. (1974) The economics of resources or the resources of economics. The American Economic Review, 64(2), 1-14.

Sotchava, V. B. (1978). Por uma teoria de classificação de geossistemas de vida terrestre. São Paulo: IGEO/USP.

UNESCO - Organização das Nações Unidas para Educação, a Ciência e a Cultura. (2005). Década da educação das Nações Unidas para um desenvolvimento sustentável, 2005-2014: Documento final do esquema internacional de implementação. Recuperado de: <http://www.unesco.org/new/pt/brasilia/about-this-office/prizes-and-celebrations/2005-2014the-united-nations-decade-of-education-for-sustainable-development>.

UNESCO - Organização das Nações Unidas para Educação, a Ciência e a Cultura. (2006). Framework for the UNDESD international implementation scheme. Recuperado de: <http://unesdoc.unesco.org/images/0014/001486/148650E.pdf>.

Veiga, J. E. da. (2005). Desenvolvimento sustentável: O desafio do século XXI. Rio de Janeiro: Garamond.

Wright, T. S. A. (2002). Definitions and frameworks for environmental sustainability in higher education. International Journal of Sustainability in Higher Education, 3(3), 203-220. 